\title{
Debate sobre a Teoria dos Blocos Semânticos e a Semântica do Acontecimento: quase-bloco, locutor-posição e espaço de enunciação
}

\author{
Debate on the Theory of Semantic Blocks and Semantic of Event: \\ quasi-block, speaker-position and space of enunciation \\ Marion Carel \\ École des Hautes Études en Sciences Sociales - Paris - França ${ }^{1}$ \\ Julio Cesar Machado \\ Universidade do Estado de Minas Gerais - Unidade de Passos, e \\ Centro Estadual de Educação Continuada "Alda Polastre" - Minas Gerais - Brasil2 \\ $\diamond$
}

\begin{abstract}
Resumo: o projeto deste debate objetivou estabelecer um (raro) momento de reflexão sobre alguns temas caros à Linguística no Brasil segundo a óptica da teoria francesa intitulada Teoria dos Blocos Semânticos (TBS). Fundada em 1992 pela Dra. Marion Carel, a TBS é considerada a versão mais radical da teoria antes chamada Teoria da Argumentação na Língua, desenvolvida inicialmente por Jean-Claude Anscombre e Oswald Ducrot. Este debate tomou profundidade teórica rica e inédita, e devido à condição técnica dos temas abordados, bem como ao modo teórico das questões e respostas, a discussão ganhou cunho particular, motivo pelo qual demos um nome para este debate, que bem the sumariasse no rol das pesquisas sobre a TBS. Esperamos, assim, traçar um diálogo, no sentido acadêmico bem positivo desta palavra, entre os modos de raciocínio francês e brasileiro, no quadro que aqui dispomos, e esperar boas continuidades a partir deste debate.
\end{abstract}

Palavras-chave: Blocos Semânticos; Quase-Bloco; Polifonia; Enunciação

\begin{abstract}
: the project of this discussion aimed to establish a (rare) moment of reflection on some themes dear to Linguistics in Brazil from the viewpoint of French theory called Theory of Semantic blocks (TBS). Founded in 1992 by Marion Carel, the TBS is considered the most radical version of the theory formerly called Theory of Argumentation in Language, initially developed by Anscombre and Ducrot. This debate has taken unprecedented rich and theoretical depth, and due to the technical condition of the themes and the theoretical way of questions and answers, the discussion gained particular flavor, which is why we gave a name to this debate, that well summaries him in the list of TBS's researches. We thus hope to draw a dialog in the very positive academic sense of this word, between modes of French and Brazilian reasoning, in the frame we have here, and expect good continuity from this debate.
\end{abstract}

Keywords: Semantic blocks; Quasi-Block; Polyphony; Enunciation

\footnotetext{
1 À présent, j'aimerais remercier la professeur Sra. Marion Carel d'avoir bien voulu accepter de me diriger lors de mon stage de recherche au niveau Doctoral à l'École des Hautes Études en Sciences Sociales de Paris, en France. J'aimerais la remercier également pour sa rigueur et sa profondeur théorique. En mon nom, et au nom de mon groupe de recherche, $\mathrm{j}$ 'aimerais lui offrir mes remerciements les plus sincères.

2 Agradeço também às minhas agências fomentadoras de Doutorado, na França: CAPES - PDSE, e no Brasil: SRE-MG; FESP; e PAEx/UEMG.
} 


\section{Introdução}

Desde a sua fundação, a TBS vem se consolidando cada vez mais enquanto um saber plausível para as ciências da linguagem, sobremaneira europeia. Por consequência, seria interessante escutar como esta teoria se portaria diante de certas questões importantes na contemporaneidade, na Linguística, e no Brasil. Muitas das questões sobre as quais ainda não se tem registro de publicação.

Nesta linha, a Dra. Marion Carel, professora da École des Hautes Études en Sciences Sociales (EHESS), em Paris, na França, que atualmente desenvolve a TBS juntamente com o Dr. Oswald Ducrot, debaterá as questões por mim propostas, agrupadas em três temas.

\section{Primeiro tema: a atualidade da TBS}

- Julio Machado: Esta questão diz respeito a um problema de localização teórica. Nós podemos entender que a TBS é, de certa forma, uma teoria dialógica, uma vez que ela está enraizada em moldes da Lógica (mas não partilha todas as suas hipóteses), e é formulada com base na Teoria da Argumentação na Língua. E ainda: ela se aproxima fortemente do estruturalismo saussuriano, e assume interesses pragmáticos no que concerne a funcionamento de frases, enunciados (situações, contexto, polifonia etc). Mas ela implica afastar-se decididamente da semântica vericondicional de Frege. A questão que se põe é: se necessário fosse, onde poderíamos localizar exatamente a TBS na Linguística, e como se faria esta filiação e delimitação?

$\square$ Marion Carel: A TBS é uma formulação radical da Teoria da Argumentação na Língua, de Anscombre e Ducrot. As pesquisas tradicionais admitem que a significação linguística das palavras e das frases é informativa. Anscombre e Ducrot propuseram de somar à significação informativa uma significação argumentativa porque - é o que mostram seus trabalhos - a significação argumentativa não se deduz da significação informativa.

Por exemplo: "Pedro quase terminou" comunica a mesma informação que "Pedro não terminou", mas tem a mesma direção argumentativa que "Pedro terminou". A TBS é radical quando ela aceita uma significação argumentativa, mas não admite mais nenhuma significação informativa. O que, às vezes, complica um pouco a interpretação da TBS, é que ela é uma teoria relativamente técnica. Isto lhe dá um ar matemático que a faz parecer com as teorias informativas, como aquela de Frege. Mas esta disposição é tudo o que ela divide com as teorias informativas.
- Julio Machado: $O$ Estruturalismo é um dos clássicos e respeitados braços da Linguística, num panorama mundial, mas muito criticado em muitos manuais de semântica brasileiros, de modo superficial, eu diria, quando estes manuais pretendem totalizar e resumir o Estruturalismo em uma única "concepção de raciocínio fechada", excluindo uma gama infinda de outros interesses e estudos caros a vários estruturalismos - entendo que não podemos falar de um único estruturalismo -. Temos como exemplo, o seu estruturalismo, de alto interesse enunciativo, nos seu livro recente. Diante disto, e neste quadro, perguntamos: o que significa ser estruturalista nos dias atuais, com todas as dinâmicas da língua moderna: imagética, musical, abreviada, fluída na internet, na televisão e toda particular dos/nos celulares?

$\square$ Marion Carel: Fundamentalmente, eu penso que o conhecimento do mundo não nos diz nada da língua. A regra da palavra "faca", em um texto, não reflete em nada as propriedades que as facas possuem no mundo. A TBS é estruturalista naquilo que ela não explica as propriedades das palavras da língua, ou dos textos, por propriedades físicas ou psicológicas dos objetos ou dos seres do mundo. A língua é, então, o único sistema "argumentativo"? Eu não creio. Eu admito, assim, atualmente - sem outra razão que apenas uma certa intuição - que uma interação é possível entre imagens e textos. O que as imagens comunicam me parece parafraseável, frequentemente, por encadeamentos argumentativos. Dois exemplos.

Um primeiro exemplo é dado pelas "danças macabras":

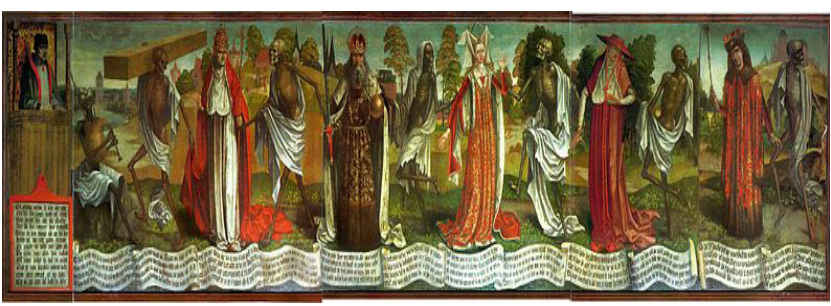

Danse Macabre - Bernt Notke ${ }^{3}$

Elas dizem respeito a pinturas feitas sobre os muros das igrejas na época da epidemia da peste negra (por volta de 1350). Elas representam personagens (o papa, o imperador, o rei, o duque ... o advogado... o músico... o camponês, ... o recém-nascido) em farandoles, cada um acompanhado de um esqueleto que o leva. Estas danças macabras comunicam que a morte toca todo mundo. Em particular, elas comunicam: mesmo se alguém é poderoso,

3 Domínio público. Disponível em: <https://upload.wikimedia.org/ wikipedia/commons/5/58/Bernt_Notke_Danse_Macabre.jpg $>$. 
ele não pode escapar da morte (PODEROSO PT NEG CONSEGUIR) 4 .

Um segundo exemplo é dado pelas tiras desenhadas (ou os desenhos de imprensa humorísticos), neles, o desenho e as palavras colaboram para comunicar conteúdos argumentativos. Vemos, por exemplo, um homem cercado de pilhas de livros dizer "Eu quero ser amado": deve-se compreender mesmo que este homem seja um intelectual, ele é infantil.

Claro, as imagens que eu tomei como exemplo não comportam nenhum signo que pareceria a conjunção "portanto" ou a conjunção "no entanto". Mas somos convidados, e conseguimos instaurar uma. O entrelaçamento argumentativo subjacente à língua me parece poder existir em outros sistemas. E isto é aqui uma surpresa para mim - e portanto uma pequena descoberta - porque isto retém que eu estudo o sistema da língua nela mesma, sem me inspirar em outra coisa: isto é surpreendente (não circular) por encontrar em alguma coisa onde nós não tínhamos encontrado.

Julio Machado: Nas aulas do ano letivo [2013-2014] de que tive a honra de participar, a senhora e Oswald Ducrot propuseram o conceito inédito, ainda não publicado, de "quase-bloco". Durante as aulas, a senhora e Ducrot esmeraram-se por apresentar o quasebloco em dois tipos: quase-bloco converso - X DC Y + $X$ PT NEG-Y; e quase-bloco transposto - NEG-X DC $N E G-Y+N E G-X P T Y$; no modelo metodológico da TBS, em três formatos:

I. Conteúdo standart (há um aspecto argumentativo, e há um encadeamento argumentativo);

II. Conteúdo conceitualizante (não há aspecto, mas há um encadeamento);

III. Conteúdo concretizante (há um aspecto, mas não há encadeamento)

Nossa questão, então, pretende-se um pouco longa, talvez, mas mesmo assim a faremos: a senhora poderia, a partir desta síntese de dois tipos e três formas da nova noção, nos dar uma definição daquilo que a senhora e Ducrot chamam de quase-bloco, e falar um pouco sobre estes tipos e formas?

$\square$ Marion Carel: Vou dividir a resposta em duas partes:

\section{(1) O sentido dos termos isolados: aspectos argu- mentativos e quase-blocos}

Os quase-blocos foram introduzidos para melhor descrever a significação das palavras. Nesta última, até aqui, supunha-se comportar unicamente aspectos

\footnotetext{
4 A notação básica da TBS é: DC - portanto; PT - no entanto; e NEG negativo (nota do debatedor)
}

argumentativos que nós dividíamos em duas partes da significação, a argumentação interna e a argumentação externa. Retomemos o eterno exemplo de "prudente": sua argumentação interna continha PERIGO DC PRECAUÇÃO, e sua argumentação externa continha os dois aspectos conversos PRUDENTE DC SEGURANÇA e PRUDENTE PT NEG-SEGURANÇA. Nós mantemos a hipótese cuja significação de "prudente" contém o aspecto PERIGO DC PRECAUÇÃO. Ao contrário, nós dizemos agora que ele não contém nenhum dos dois aspectos PRUDENTE DC SEGURANÇA e PRUDENTE PT NEG-SEGURANÇA. O que ele comporta, é a alternativa destes dois aspectos, e não estes dois aspectos; ele comporta aquilo que eles possuem em comum, estes dois, e nenhum outro aspecto do mesmo bloco; a significação de "prudente" comporta o quase-bloco PRUDENTE (SEGURANÇA) que são provenientes, cada um, de dois aspectos conversos: PRUDENTE DC SEGURANÇA e PRUDENTE PT NEG-SEGURANÇA.

Do mesmo modo, nós inserimos na argumentação externa de "prudente" os dois aspectos transpostos RESPONSÁVEL DC PRUDENTE e NEG-RESPONSÁVEL PT PRUDENTE. É agora a alternativa mesma destes dois aspectos que nós colocamos na significação de "prudente", o que significa dizer que estes dois aspectos, e somente eles, dividem, a saber, o quase-bloco (RESPONSÁVEL) PRUDENTE.

Segundo a relação que sustenta os dois aspectos oriundos de um quase-bloco, eu falava em 2013-2014 de quase-bloco de conversos (é o caso de PRUDENTE (SEGURANÇA)) e de quase-bloco de transpostos (é o caso de (RESPONSÁVEL) PRUDENTE). Eu creio que estes complementos de nome ("de conversos", "de transpostos") são maus termos técnicos porque eles aludem demasiadamente aos aspectos oriundos do quasebloco, e não ao quase-bloco, ele mesmo. Mas eu não sei bem ainda por quais termos lhes substituir.

A introdução da noção de quase-bloco permitiu pôr em evidência vínculos entre palavras que não tinham até então chamado nossa atenção.

Cada aspecto é, em efeito, oriundo de dois quaseblocos. Por exemplo, PERIGO DC PRECAUÇÃO é oriundo do quase-bloco de conversos PERIGO (PRECAUÇÃO), e do quase-bloco de transpostos (PERIGO) PRECAUÇÃO.

A palavra "prudente", que significa PERIGO DC PRECAUÇÃO, é assim formalmente, em relação com a palavra "perigo", que significa PERIGO (PRECAUÇÃO), e com a palavra "precaver", que significa (PERIGO) PRECAUÇÃO.

Intuitivamente, é com "precaver" que o adjetivo "prudente" parece aparentar semanticamente. Seu significado PERIGO DC PRECAUÇÃO é oriundo do significado 
(PERIGO) PRECAUÇÃO de "precaver"; "prudente" é uma maneira de "precaver". A significação de "prudente" é (em parte) construída à parte daquela de "precaver".

Uma filiação (imaginária, eu não creio que ela seja diacrônica) se estabelece assim entre palavras, filiação que eu me proponho, nos meus próximos trabalhos, de explorar. Darei três exemplos dela.

O primeiro exemplo concerne aos paradoxais. A introdução da noção de quase-bloco nos permitiu melhor formular a noção de paradoxo linguístico. Nós podemos dizer agora que um aspecto argumentativo é doxal se e somente se ele adveio de um quase-bloco lexicalizado. Por exemplo, PERIGO DC PRECAUÇÃO é doxal porque ele adveio do quase-bloco (PERIGO). Por exemplo, PERIGO DC PRECAUÇÃO é doxal porque ele é oriundo do quase-bloco (PERIGO) PRECAUÇÃO que é lexicalizado (ele pertence à significação "precaver"). A filiação da qual eu falava no parágrafo precedente é a razão da doxicalidade linguística.

Inversamente é paradoxal um aspecto que é contrário a esta filiação. Por exemplo, o aspecto SOFRIMENTO DC FELICIDADE, lexicalizado em "masoquista", não é doxal: este elemento da significação de "masoquista" não provém de uma filiação de "masoquista" não provém de uma filiação de "masoquista" com "sofrimento" ou "felicidade". Ele é mesmo contrário à esta filiação que conduz à SOFRIMENTO DC NEG FELICIDADE. O aspecto SOFRIMENTO DC FELICIDADE é paradoxal.

O segundo exemplo concerne à indecisão semântica de certas palavras. Nós havíamos notado que a significação de uma palavra como "bobo" hesita entre o aspecto DIFÍCIL DC NEG COMPREENDER e o aspecto NEG DIFÍCIL PT NEG COMPREENDER. Eu tinha me dado conta disto dizendo que o quase-bloco (DIFÍCIL) NEG COMPREENDER, lexicalizado em "não compreender", está em curso de transformação: o aspecto não é ainda escolhido, a significação da palavra "bobo" está neste entre-dois. "Ser bobo", é não compreender, mas não sabemos ainda exatamente sob qual forma. $\mathrm{Eu}$ vou tentar fazer, agora, um pequeno desenho:

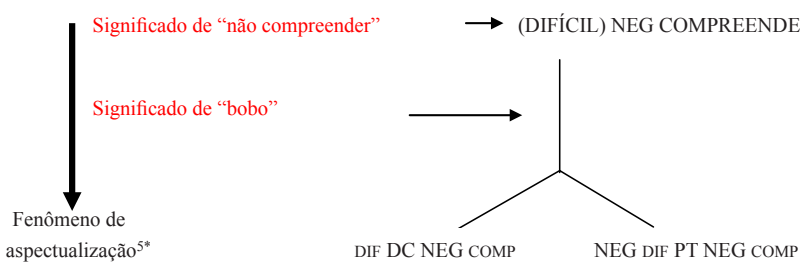

O terceiro exemplo concerne às relações entre argumentação interna e argumentação externa das

\footnotetext{
5 Eu chamo "aspectualização" o fenômeno que transforma um quase-bloco em um dos dois aspectos que são oriundos dele (nota de Marion Carel).
}

palavras. Não existe, às vezes, nenhuma coerência entre argumentação externa e argumentação interna. $\mathrm{O}$ dado da argumentação interna não é suficiente para prever a argumentação externa. Assim, as palavras "indulgente" e "negligente" significam todas as duas o aspecto FALTA PT NEG PUNIR, mas o primeiro é favorável, e o segundo, desfavorável. A argumentação externa de "indulgente" contém, portanto, os dois aspectos QUALIDADE DC APPRECIAR e QUALIDADE PT NEG APPRECIAR, do bloco da qualidade-apreciada, enquanto que a argumentação externa de "negligente" conteria os dois outros aspectos: NEG QUALIDADE DC NEG APRECIAR e NEG QUALIDADE PT APPRECIAR deste mesmo bloco. Eu direi agora que as significações de "indulgente" e de "negligente" são construídas a partir da significação de "não punir", por acréscimo. A expressão "não punir" significa o quasebloco (NEG FALTA) NEG PUNIR, e "indulgente" como "negligente" vai significar o aspecto FALTA PT NEG PUNIR: nesta medida, as significações de "indulgente" e a significação de "negligente" são construídas a partir daquela de "não punir".

Mais precisamente, as significações de "indulgente" e de "negligente" são construídas a partir da significação de "não punir", por acréscimo. Em efeito, a expressão "não punir" não significa nenhum dos aspectos ou dos quase-blocos da Qualidade-Apreciada. Na significação de "indulgente" é acrescido o quase-bloco QUALIDADE (APRECIAR); e mesmo, na significação de "negligente", é acrescido o quase-bloco complementar NEG QUALIDADE (NEG APRECIAR).

Não há, portanto, no caso de "indulgente" e de "negligente", nenhuma coerência entre o aspecto significado (FALTA PT NEG PUNIÇÃo) e o quase-bloco significado (respectivamente QUALIDADE (APRECIAR) e NEG QUALIDADE (NEG APRECIAR)). Em outros casos, de modo contrário, uma certa coerência se observa. Assim, a palavra "faca" significa DURO PT CORTA: uma faca permite cortar mesmo o que é duro. Por outro lado, a palavra "faca" significa o quase-bloco CORTA (PERIGOSO). Uma certa coerência parece assim se instaurar entre os dois elementos que a palavra "faca" significa. Nós podemos agora formulá-la (sem abandonar a hipótese que o bloco semântico não é analisável em dois metapredicados DURO e CORTA). A significação de "faca" provém da signicação de "cortar", e nela reteve muitos elementos: de uma parte "faca" aspectualiza o quase-bloco (NEG DURO) CORTA, e de outra parte, "faca" retém nela, tal qual, o quase-bloco CORTA (PERIGOSO).

\section{(2) Os diversos formatos de conteúdo dos enun- ciados}

Nós distinguimos, um pouco próximo a todos os semanticistas, o valor semântico de um sintagma, e o 
valor semântico de uma frase (eu tomo aqui "frase" no sentido banal de um segmento de palavras comportando, dizemos, ao menos um sujeito e um verbo; eu não faço a diferença entre frase e enunciado).

No que tange à significação dos sintagmas, nós mudamos de posição naquilo que nós supúnhamos inicialmente, que a significação era composta unicamente de aspectos, e nós supomos agora que a significação contém, por sua vez, aspectos e quase-blocos. No que concerne à significação de frases, nós mudamos duas vezes de posição.

\section{Primeira posição}

Nós supomos, de início, que os termos significam aspectos, e que "Pedro é prudente" significa um encadeamento argumentativo, isto é, um discurso religando duas proposições gramaticais por uma conjunção do tipo "portanto" ou do tipo "no entanto". O termo "prudente" significa, assim, o esqueleto do encadeamento signifcado por "Pedro é prudente"; a significação de termos prefigura o sentido argumentativo dos enunciados.

\section{Segunda posição}

A análise de enunciados é, por sua vez, um pouco complicada, porque, de uma parte, os encadeamentos são ambíguos, e, de outra parte, os enunciados levantam, às vezes, esta ambiguidade.

Os encadeamentos são ambíguos no sentido de que, por exemplo, o encadeamento ela pensou ser vista, $e$, portanto, ficou vermelha pode ter por esqueleto tão bem PENSAMENTO AGRADÁVEL DC SENSAÇÃO AGRADÁVEL, quanto PENSAMENTO DESAGRADÁVEL DC SENSAÇÃO DESAGRADÁVEL. Os enunciados levantam, às vezes, a ambiguidade naquilo que o enunciado o prazer de ser vista a fez ficar vermelha é parafraseável por ela pensou no fato de ser vista, e, portanto, ficou vermelha, compreendido como provindo de PENSAMENTO AGRADÁVEL DC SENSAÇÃO AGRADÁVEL.

Nós mantemos, então, a hipótese de que os termos significam aspectos, mas fizemos a hipótese de que todo enunciado levanta a ambiguidade do encadeamento que ele evoca: as frases significam, assim, encadeamentoscompreendidos-como-concretizando-tal-aspecto. O conteúdo de um enunciado era sempre constituído de um encadeamento, acompanhado do aspecto argumentativo que lhe fixava o sentido exato.

\section{Terceira e última posição}

Nós supomos que os termos significam aspectos e quase-blocos. Certos enunciados comunicam encadeamentos compreendidos como concretizando tal aspecto, bem definido. É o que chamo agora de caso standard, e eu qualifico de conteúdo standard um encadeamento argumentativo associado ao aspecto argumentativo que lhe constitui o esqueleto.

Nós dizemos que o encadeamento argumentativo concretiza o aspecto argumentativo. Eu insisto sobre o fato de que um conteúdo standard é um conteúdo de um enunciado; não é o conteúdo de uma palavra. Nós podemos fazer um pequeno desenho do caso standard:

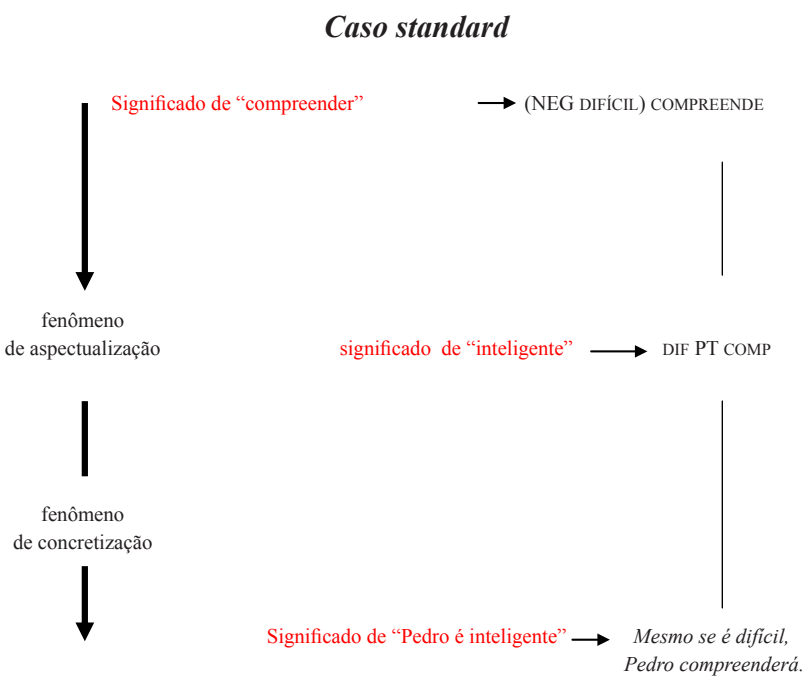

À margem deste caso standard, existe, eu penso, dois outros casos: o conteúdo de um enunciado (um enunciado, e não um termo, eu o repito) pode ser "especificante" ou ele pode ser "conceitualizante" (Eu acabo de mudar um pouco minha terminologia das aulas de 2013-2014, para não confundir todos os fenômenos).

Assim, o enunciado Pedro obteve uma boa nota pode parecer um pouco ambíguo: por certo, obter uma boa nota é sinônimo de sucesso, mas Pedro foi bem sucedido mesmo por que foi difícil, ou por que foi fácil? $\mathrm{O}$ enunciado não o diz. O grupo verbal obter uma boa nota significa não um aspecto argumentativo como no exemplo standard, mas um quase-bloco - (FÁCIL) SUCESSO. O fenômeno de concretização não finda porque não houve procedimento de aspectualização: eu notei aqui (FÁCIL)SUCESSO $\downarrow$ o resultado deste trabalho de especificação:

\section{Caso especificante}

(a especificação está em curso)

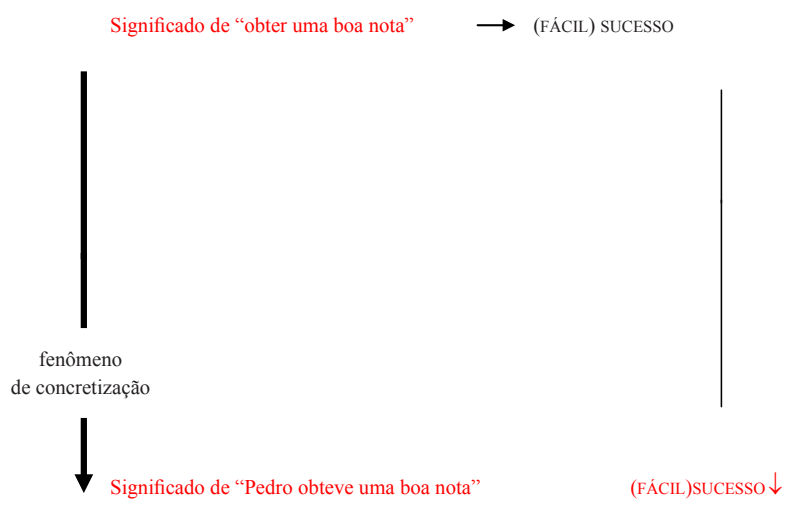

Nós não podemos encontrar um encadeamento que parafraseia o enunciado; o enunciado não é totalmente 
interpretado. Imaginemos que o enunciado "Pedro obteve uma boa nota" é dito por uma professora aos parentes de Pedro. Os parentes de Pedro vão então fazer perguntas para tentar determinar o aspecto, perguntas como: "e os outros, eles obtiveram também uma boa nota?": se a resposta for sim, os parentes serão levados ao conteúdo standard foi fácil, portanto, Pedro obteve uma boa nota, compreendido como concretizando FÁCIL DC SUCESSO; se a resposta é não, os parentes serão levados ao conteúdo standard mesmo que fosse difícil, Pedro obteve uma boa nota, compreendido como concretizando NEG FÁCIL PT SUCESSO.

Ao contrário, nós podemos imaginar que certos enunciados não especificam o aspecto argumentativo concretizado. É o caso da passagem de Flaubert:

Uma noite do mês de agosto (ela tinha, então, dezoito anos), eles a levaram para a assembléia de Colleville. Neste ínterim, ela ficou aturdida, estupefata pelo escândalo dos violinistas, as luzes nas árvores, a miscelânea dos costumes, os desenhos, as cruzes de ouro, esta massa de mundo saltando à sua vez (FLAUBERT, 2010).

O locutor enumera exemplos sem supor que a natureza da qual eles são exemplos já possui um nome: a conceitualização está somente em curso. O exemplo de Flaubert evoca encadeamentos sem que o locutor suponha (cf a ausência de $e$ ) que a reação de Felicidade tenha um nome, e que o intérprete tenha que o descobrir:

- Os violinistas faziam escândalo, portanto, ela ficou aturdida (ou estupefata)

- As luzes brilhavam nas árvores, portanto, ela ficou aturdida (ou estupefata)

O conteúdo do exemplo de Flaubert é conceitualizante. Ele é constituído de encadeamentos "apontando" para um aspecto que não é ainda construído e que os encadeamentos servem para construí-lo. Nós poderemos notá-lo: (os violinistas faziam escândalo, portanto ela ficou aturdida).

Julio Machado: No seu livro de 2011a, "L'entrelacement argumentatif" (Oentrelaçamento argumentativo), a senhora propôs a noção de "concordar" enquanto uma atitude do locutor, como uma noção técnica (parece que) no lugar da noção técnica clássica de "pressuposição". A senhora poderia nos explicar a dinâmica e os limites desta nova noção de "concordar", e dizer se a noção de pressuposição ainda tem lugar na TBS?

$\square$ Marion Carel: É uma questão importante, sobre a qual eu consagrei um artigo: "la polyphonie linguistique" (a polifonia linguística), no primeiro número da revista on-line "transposition".
Julio Machado: Sobre este artigo que a senhora cita (CAREL, 2011b), queremos deixar marcado aqui que ele foi traduzido para o português pela linguista brasileira Dra. Leci Borges Barbisan, que faz um trabalho tanto de tradução como de reflexão, muito sério e fiel ao modo de raciocínio da senhora e de Ducrot, no Brasil. Vamos deixar aqui o link do seu artigo que trata desta questão da nova noção de "concordar", e da clássica noção de pressuposto. Original em francês: <http://transposition-revue.org/les-numeros/polyphonie-et-societe/ article/la-polyphonie-linguistique $>$; Tradução: $<$ http:// revistaseletronicas.pucrs.br/ojs/index.php/fale/article/ view/9218/636>.

\section{Segundo tema: diálogos entre a TBS e teorias brasileiras}

- Julio Machado: As minhas próximas questões têm como estratégia pôr em confronto reflexivo a TBS com o modo analítico-linguístico brasileiro, especificamente com uma teoria brasileira: a Semântica do Acontecimento, desenvolvida pelo brasileiro Eduardo Guimarães. Teoria que ele considera autônoma na Linguística, e que, para sua elaboração, valeu-se grandemente dos trabalhos de Ducrot, por um lado; e de Pêcheux, por outro.

Assim, para poder delinear bem a especificidade da minha próxima questão, de cunho teórico, vou antes supor a situação seguinte: consideremos que há um porta-voz oficial de um governo que trabalha duro para este governo. Ele não só trabalha para o governo, ele confia no governo. Ele ama o governo. Mas, como todos os apaixonados, alguns pontos não o satisfazem, ele concorda com certos pontos do governo. Por isto, este porta-voz afirma algumas vezes que o governo é bom, mas algumas vezes ele afirma o enunciado.

Este governo não é bom.

É sobre este enunciado, nestas condições, que quero chamar a atenção e elaborar minha questão para a senhora. Prossigo: deixando este enunciadoalvo de lado por ora, explico que Guimarães propôs a noção de "locutor-posição" para poder pensar o sentido dos enunciados (GUIMARÃES, 2002). De modo fortemente afetado pelos trabalhos de Pêcheux, ele afirma categoricamente que todo sentido é indesviável de uma posição social (dentista, professor, político, presidente, jornalista etc). Só se fala de sentido nesta teoria na medida em que se fala em posição-sujeito. Não há sentido sem lugar social, para Guimarães. Mesmo que eu discorde parcialmente deste postulado, esta noção de locutor-posição é interessante para poder visualizar minúcias do enunciado acima, como: 
"este enunciado é característico da posição-sujeito de 'locutor-porta-voz', que fala de modo positivo do seu governo, MAS paradoxalmente fala igualmente de modo pejorativo do seu governo." 6

Este enunciado, nestas condições, causa um estranhamento para a noção de posição-sujeito porque é paradoxal, e acredito que cause estranhamento em outras teorias também, já que o paradoxo é um problema para qualquer teoria. A Semântica do Acontecimento explicaria o enunciado acima ainda por vias de estabelecer lugar(es) exato(s), inteiro(s), como: porta$v o z+$ crítico, por exemplo. Mas há algo do enunciado que advém da posição porta-voz, e algo ali mesmo que contraria esta mesma posição. Parece que este enunciado tem dificuldades de se filiar a uma "posição de direita", e outra "posição de esquerda" ao mesmo tempo, por se tratar de um paradoxo de posição: propagandearultrajar o governo simultaneamente, e que nos obriga a ver/operar este enunciado de outros modos, conforme a exigência de todo paradoxo.

Já posso colocar minha questão: primeiro, como a TBS lidaria com este paradoxo acima? Segundo, seria pertinente pensar esta noção de locutor-posição, ou outra noção técnica próxima, não-geográfica, nãovericondicional, mas enunciativo-estrutural, no quadro da TBS, para explicar a questão que Guimarães chama locutor-posição?

$\mathrm{Na}$ verdade, esta pergunta pede que a senhora discorra sobre o que nós dois já conversamos em outros momentos: fale um pouco sobre a possibilidade que a senhora me apresentou de pensar a noção de locutorposição pela TBS, a partir da sua proposta de quasebloco:

intuição de uma posição social
[próximo de X DC falar bem de X]
+
aquilo que foi dito
[próximo de X PT NEG-falar bem de X].

(onde $X$, no caso de nosso enunciado, pode ser o governo)

$\square$ Marion Carel: Parece-me que este enunciado [Este governo não é bom] pode ser diversamente analisado, conforme comparemo-lo a um enunciado da mesma frase com um oposto ao governo, ou que o comparemos a enunciados precedentes dos mesmos locutores, como: "Este governo é bom".

\footnotetext{
6 É importante marcar aqui que os estudos atuais do MAS (CAREL, 2011a) não apresentam mais apenas dois segmentos contrários com negação total de um pelo outro, como se fazia na década de oitenta, mas trabalham agora, de modo mais atual e refinado, dois segmentos que se misturam, uma negação parcial entre os dois segmentos contrários.
}

Enquanto nós o comparamos a um enunciado da mesma frase com um oposto ao governo, parece que "não bom" não tem o mesmo sentido: na boca do opositor do governo, ele significa "este governo possui tal e tal tese política, portanto, ele não é bom"; na boca do porta-voz oficial ele significa, por exemplo, "este governo não é voluntarioso, portanto, ele não é bom".

Agora, o enunciado do porta-voz oficial pode igualmente ser comprendido como fazendo alusão à sua proximidade ao governo, ele seria equivalente a "eu sou próximo deste governo, mas eu não creio que ele seja bom”. Seriam então comunicados os encadeamentos:

- O locutor concorda, conforme o primeiro segmento do "mas": "Eu sou próximo deste governo, portanto, eu não questiono suas teses".

- O locutor exclui uma má interpretação de seu "eu não creio que ele seja bom", que seria "Eu não sou próximo do governo, portanto, eu não creio que ele seja bom".

- O locutor põe "este governo não é voluntarioso, portanto, eu não creio que ele seja bom".

Esta segunda interpretação enriquece a primeira, multiplicando os conteúdos, sem lhes opor.

Uma terceira interpretação - esta, perece-me, que sugere esta sua pergunta - é que o enunciado fez alusão ao fato que é próximo a seus dizeres precedentes. Eu direi, então, que o locutor comunica, em primeiro lugar, o encadeamento em PT: "Eu sou próximo do governo, e, no entanto, não creio que ele seja bom". O caráter transgressivo do encadeamento marca, por ele mesmo, que o encadeamento é inesperado, que o normal teria sido que o porta-voz oficial falasse bem do governo.

Mas isso é tudo? O locutor se contenta em pôr este encadeamento transgressivo? Nós temos, assim, nos perguntado se, às vezes, a evocação de um encadeamento transgressivo não se acompanharia sempre da exclusão do encadeamento normativo converso. Eu não o creio. Eu não creio que isso seja uma regra geral. Mas, às vezes, sim, nós podemos imaginar que a atitude de $p \hat{r} r$ o encadeamento transgressivo é acompanhada da exclusão do encadeamento normativo. Isto é, em particular, o caso aqui, pode ser pelo emprego da negação "não" no enunciado "Este governo não é bom". Nós podemos dizer que:

- O locutor exclui: "Eu sou próximo do governo, portanto, eu creio que ele seja bom".

- O locutor põe: "Eu sou próximo do governo, no entanto, eu não creio que ele seja bom".

Você nota, então, e isto está totalmente no espírito dos quase-blocos, que o locutor, ali, evitando se descrever pelo modo do aspecto normativo SER PRÓXIMO DE X DC FALAR BEM DE X, se descreve antes pelo modo do quasebloco SER PRÓXIMO DE X (FALAR BEM DE X). Haveria, na 
sua palavra, como um movimento inverso ao fenômeno de aspectualização, do qual eu falava anteriormente: nós poderíamos falar de movimento de abstração.

Julio Machado: Para colocar minha próxima questão, ainda nesta linha de diálogo teórico BrasilFrança, vou retomar uma das discussões que já discuti com a senhora em nossas reuniões. Consideremos as seguintes situações: se alguém enunciou "Eu tenho um explosivo aqui!", nos diferentes lugares abaixo, nota-se que o sentido das palavras vai mudar segundo o lugar onde a pessoa se encontra, assim:

- Em um curso de química, se alguém diz "Eu tenho um explosivo aqui!": a senhora disse-me que temos aqui um sentido motivador

- Em um aeroporto, se alguém diz "Eu tenho um explosivo aqui!": a senhora disse-me que temos um sentido inquietante

Quero marcar que, segundo Eduardo Guimarães, a diferença entre estes sentidos é devido a, pelo menos, dois fatores: (1) de regularidades do dizer próprias de espaços diferentes, operados pela noção de "espaço de enunciação". Assim, em um curso de química, será possivel, normal, enunciar "explosivo", contrariamente ao que poderia se passar em um aeroporto); e (2) de discursos precedentes que afetam o sentido do enunciado, explorados pela noção de "memorável". Assim, podemos nos perguntar por que é bom enunciar "explosivo" em um espaço, e mau enunciar "explosivo" em um outro espaço? Nesta linha brasileira, seria por razões históricas, por discursos precedentes que afetam o sentido do enunciado.

Já posso pôr minha questão: seria pertinente pensar em uma noção técnica (ou próxima) da de "espaço de enunciação”, como uma percepção semânticoestrutural, materialmente marcada ou não, significada em cada discurso, perceptivel apenas no enunciado (não no mundo), para explicar a diferença entre o sentido motivador do "espaço de enunciação - curso de química": EXPLOSIVO DC OBJETO INTERESSANTE, e o sentido inquietante do "espaço de enunciação aeroporto": marcado pelo memorável de discursos precedentes EXPLOSIVO DC PERIGO?

Marion Carel: Deve-se efetivamente distinguir o sentido do enunciado "Eu tenho um explosivo aqui!" em um aeroporto e em um curso de química. No primeiro caso, a palavra "explosivo" é argumentativamente importante: é ela que dá seu sentido ao enunciado global que evocará uma argumentação do tipo EXPLOSIVO DC PERIGO. No segundo caso, me parece que a palavra "explosivo" não é argumentativamente importante. É antes o grupo verbal "ter aqui" que dá seu sentido ao enunciado global que evocará, então, uma argumentação como "Eu tenho um explosivo aqui, portanto, venham se juntar a mim".
A questão que você põe concerne aos modos que o interlocutor dispõe para levantar a ambiguidade. Eles não são necessariamente linguísticos: a situação por si só, um curso de química ou um aeroporto, basta para levantá-la. Dever-se-ia, portanto, construir, como o senhor propõe, à esteira de Guimarães, uma noção de espaço de enunciação.

O trabalho não foi feito na França, e eu estou muito interessada em trabalhos que construirão esta noção de espaço de enunciação sem lhe reduzir, claro, a um lugar geográfico.

Dever-se-ia, pode ser, começar pelos casos onde a presença do espaço de enunciação é marcada em discursos e, assim, estudar a regra de "aeroporto" - ela conduzirá a comparar estes espaços de enunciação aos espaços mentais de Fauconnier .

Dever-se-ia, em seguida, se perguntar como, sem marca linguística, nós chegaremos a recuperar situacionalmente estes "espaços de enunciação". É um objeto muito interessante.

\section{Terceiro tema: a TBS enquanto um objeto de interesse dos brasileiros}

- Julio Machado: Uma última questão, agora tomando a TBS enquanto um objeto de interesse para o espaço brasileiro, especificamente o educacional. Ssabemos que, de modo geral, vemos a TBS enquanto um método científico, e raramente enquanto um método pedagógico. Minha questão vai nesta linha educacional.

$E$ fácil de compreender que a TBS apresenta um modelo forte que fornece um método que permite riquezas de análise, rigor de organização e uma sistematização profunda. Ela permite elevar a teoria a um alto nível de cientificidade para estudar a enunciação. Assim, é justo que esta teoria ultrapasse outros domínios, não acadêmicos, escolares, a fim de promover um método de análise de enunciado entre professores e estudantes.

A questão é: como deslocar a TBS da academia para o espaço educativo, e preparar professores ou preparar materiais que permitam à TBS ser uma ferramenta que permita analisar a língua nas escolas, ensinar alunos a escrever, e ensinar a arte de ensinar aos professores?

$\square$ Marion Carel: Eu penso que, nem Oswald Ducrot, nem eu mesma, não somos as pessoas adequadas para difundir a TBS para além dos círculos de pesquisa, porque nós estamos todo o tempo doutorando, deslocando, reformulando nossas teses. É a geração universitária seguinte que o fará, porque ela dispõe do recuo necessário para observar as teses finalmente imutáveis da TBS. Assim, é à Margot Salsmann, uma filósofa que vai defender sua tese em março de 2015, que eu confiei à l'EHESS o ensino da TBS aos estudantes que começam 
neste assunto. E os estudantes estão muito contentes com isto.

Uma boa difusão da TBS demandaria igualmente limitar as apresentações a alguns fenômenos centrais e lhes mostrar, obstinadamente, sobre diversos tipos de textos. Neste sentido, Margot Salsmann tem a intenção, juntamente com Alfredo Lescano, de escrever um manual. De minha parte, eu me vejo totalmente incapaz de fazer isso.

Julio Machado: Finalizando, agradeço sua atenção ao conceder este debate ao meu grupo de estudos, com toda a atenção e cuidado em responder às minhas questões e de muitos cientistas brasileiros, acuidade de atenção que é típica da senhora. Agradeço também, mais uma vez, por orientar meu Doutorado aqui em Paris, na França. E espero vê-la em breve.

$\square$ Marion Carel: Eu agradeço o seu interesse em nossas pesquisas. As suas questões me interessaram bastante. Espero que nós tenhamos outras ocasiões de discutir.

(Tradução do original francês: Julio Cesar Machado)

\section{Referências}

CAREL, Marion. L'entrelacement argumentatif: lexique, discours et blocs sémantiques. Paris : Honoré Champion, 2011a.

CAREL, Marion. A polifonia linguística. Tradução de Leci Borges Barbisan. In: Letras de Hoje, Porto Alegre, v. 46, n. 1, 2011b, p. 27-36. Disponível em: <http://revistaseletronicas. pucrs.br/ojs/index.php/fale/article/view/9218/636>.

CAREL, Marion. Atualização da polifonia. Tradução: Leci Borges Barbisan. In: Desenredo, Passo Fundo, v. 6, n. 1, p. 9-21, 2010,

FLAUBERT, Gustave. Un cour simple. Paris: Librairie Générale Française, 2010.

GUIMARÃES, Eduardo. Semântica do Acontecimento. Campinas: Pontes, 2002.

MACHADO, Julio Cesar. O paradoxo a partir da Teoria dos Blocos semânticos: língua, dicionário e história. 2015. 373f. Tese (Doutorado em Linguística) - Centro de Educação e Ciências Humanas, Programa de Pós-Graduação em Linguística/ Universidade Federal de São Carlos - PPGL/UFSCar, São Carlos-SP, 2015.

Recebido: 15 de setembro de 2015 .

Aprovado: 21 de setembro de 2015.

Contato: carel@ehess.fr,julio.semantica@gmail.com 